\title{
Author Reply
}

Anosh Sivashanmugarajah, ${ }^{1,2}$ Jordan Fulcher, ${ }^{1,2}$ David Sullivan, ${ }^{3}$ Marshall Elam, ${ }^{4}$ Alicia Jenkins, ${ }^{1,5}$ Anthony Keech ${ }^{1,2}$

${ }^{1}$ NHMRC Clinical Trials Centre, University of Sydney

${ }^{2}$ Department of Cardiology, Royal Prince Alfred Hospital, Sydney

${ }^{3}$ NSW Health Pathology, Royal Prince Alfred Hospital, Sydney

${ }^{4}$ Department of Pharmacology, University of Tennessee, Knoxville, Tennessee, USA

${ }^{5}$ Department of Medicine, University of Melbourne, St Vincent's Hospital, Melbourne

Corresponding author: Professor Anthony Keech

e-mail: Tony@ctc.usyd.edu.au

We thank Professors Somogyi and Suthers ${ }^{1}$ for their interest in our work and drawing attention to the pharmacogenetics of statin intolerance.

We agree that inherited genes influence drug pharmacokinetics and pharmacodynamics, including the risk of side effects. Using macrolide antibiotics as a practical example, we cited evidence to highlight the potential significance of variants in some cytochrome P450 enzymes in the pathogenesis of statin-associated rhabdomyolysis. ${ }^{2}$ As the correspondents state, there is a significant association between the SLCO1B1 gene T521C polymorphism and statin-related myopathy risk, but the polymorphism is not diagnostic for myopathy. ${ }^{3}$ The strongest evidence for the risk of statin-associated muscle symptoms (SAMS) related to this mutation is for simvastatin $^{4}$ and is less well-studied for other statins. The risk appears to be doserelated, and may vary in frequency by ethnicity. While the SLCO1B1 gene is by far the most robustly associated variant with SAMS, an increasing array of genetic variants are also reported to be associated with SAMS phenotypes. ${ }^{5}$

A predisposing genetic polymorphism will increase the risk of an event, such as SAMS, but the vast majority of people with a high-risk polymorphism will still not develop the event. ${ }^{6}$ Conversely, people without a high-risk polymorphism may still develop the condition. Hence, while it can be helpful to know an individual's pharmacogenetic profile, in clinical practice the diagnosis and management (with or without such genetic knowledge) still revolves around our suggested strategy of statin withdrawal and re-challenge, potentially at a lower dose or with a different statin and also careful consideration of alternate diagnoses.

Clinical pathology laboratories are already equipped with relevant instruments and skilled scientists to test for genetic markers, and already do so in cancer and some

This is the author manuscript accepted for publication and has undergone full peer review but has not been through the copyediting, typesetting, pagination and proofreading process, which may lead to differences between this version and the Version of Record. Please cite this article as doi: 10.1111/imj.14785

This article is protected by copyright. All rights reserved. 
heritable disorders, such as coeliac disease and haemochromatosis, and genetic markers may play an important role in precision medicine. If knowledge of the statin response genetic risk factor status is desired, such screening tests have recently been included in a pharmacogenomics panel available from some private pathology laboratories in Australia, but such tests are not yet subsidised by Medicare. In the meantime, such statin-related genetic studies could be applied to clinical trials and databases of statin intolerant (and tolerant) subjects and could guide intervention trials in statin intolerant subjects.

\section{References}

1. Suthers G, Somogyi A. Pharmacogenetics of statin intolerance. Intern Med J., this issue.

2. Sivashanmugarajah A, Fulcher J, Sullivan D, Elam M, Jenkins A, Keech A. Suggested clinical approach for the diagnosis and management of 'statin intolerance' with an emphasis on muscle-related side-effects. Intern Med J. 2019; 49(9): 1081-1091.

3. Hou Q, Li S, Li L, Li Y, Sun X, Tian H. Association between SLCO1B1 gene T521C polymorphism and statin-related myopathy risk. A meta-analysis of case-control studies. Medicine (Baltimore). 2015; 94(37): e1268.

4. Tuteja S, Rader JD. SLCO1B1 and statin therapy. Getting the GIST of pharmacogenetic testing. Circ Genom Precis Med. 2018; 11: e002320

5. Brunham RL, Baker S, Mammen A, Mancini G, Rosenson R. Role of genetics in the prediction of statin-associated muscle symptoms and optimization of statin use and adherence. Cardiovascular Res. 2018; 114 (8): 1073-1081.

6. Link E, Parish S, Armitage J, Bowman L, Heath S, Matsuda F et al. SLCO1B1 variants and statin-induced myopathy - a genomewide study. N Engl J Med. 2008; 359(8): 789-799. 


\section{Author Reply}

Anosh Sivashanmugarajah, ${ }^{1,2}$ Jordan Fulcher, ${ }^{1,2}$ David Sullivan, ${ }^{3}$ Marshall Elam, ${ }^{4}$ Alicia Jenkins, ${ }^{1,5}$ Anthony Keech ${ }^{1,2}$

${ }^{1}$ NHMRC Clinical Trials Centre, University of Sydney

${ }^{2}$ Department of Cardiology, Royal Prince Alfred Hospital, Sydney

${ }^{3}$ NSW Health Pathology, Royal Prince Alfred Hospital, Sydney

${ }^{4}$ Department of Pharmacology, University of Tennessee, Knoxville, Tennessee, USA

${ }^{5}$ Department of Medicine, University of Melbourne, St Vincent's Hospital, Melbourne

Corresponding author: Professor Anthony Keech

e-mail: Tony@ctc.usyd.edu.au 


\section{University Library}

\section{- M M N E R VA A gateway to Melbourne's research publications}

Minerva Access is the Institutional Repository of The University of Melbourne

Author/s:

Sivashanmugarajah, A;Fulcher, J;Sullivan, D;Elam, M;Jenkins, A;Keech, A

Title:

Pharmacogenetics of statin intolerance Reply

Date:

2020-04-01

Citation:

Sivashanmugarajah, A., Fulcher, J., Sullivan, D., Elam, M., Jenkins, A. \& Keech, A. (2020).

Pharmacogenetics of statin intolerance Reply. INTERNAL MEDICINE JOURNAL, 50 (4), pp.507-508. https://doi.org/10.1111/imj. 14785.

Persistent Link:

http://hdl.handle.net/11343/275594 